\title{
Macroeconomic effects of weather shocks, 1870-1913
}

\author{
Solomos Solomou ${ }^{1, *}$, Weike $\mathrm{Wu}^{2}$ \\ ${ }^{1}$ Faculty of Economics, Cambridge University, Austin Robinson Building, Sidgwick Avenue, Cambridge CB3 9DD, \\ United Kingdom \\ ${ }^{2}$ Business Statistics Department, Ecclesiastical Insurance, Brunswick Road, Gloucester GL1 1JZ, United Kingdom
}

\begin{abstract}
This paper considers the influence of weather shocks at a disaggregated level of analysis, modelling the effects of weather shocks on British agriculture, construction and energy demand over the period 1870-1913. The impact of weather shocks will vary from sector to sector as the conditions favouring one activity may be adverse to another. The sectoral effects are aggregated to give us an estimate of the macroeconomic effects of weather on business cycle fluctuations.
\end{abstract}

KEY WORDS: Business cycles · Climate impact

Resale or republication not permitted without written consent of the publisher

\section{INTRODUCTION}

The recent climatology literature has documented the existence of cyclical behaviour in weather variables such as temperature and rainfall (Lamb 1982). Do such 'cyclical' weather variations affect the cyclical path of production in the key weather-sensitive sectors, such as agriculture, construction and energy demand? What is the aggregate effect of weather shocks? The accepted view of economic historians (more implicit than explicit) is that weather has ceased to be a significant influence on the economic cycles of modern industrial economies. As a result, little systematic historical research has been undertaken in this area. The formulation and dismissal of particular theories about weather and business cycles have also held back research. For example, Jevons (1884, p. 235) argued for a sunspot theory of the trade cycle. ${ }^{1}$ In general, economists dismiss Jevons' theory as unconvincing and mechanical, although such ideas continue to find favour in some of the literature (Zahorchak 1983).

The starting point of this paper is to develop a more convincing historical analysis of the effect of weather on sectoral output fluctuations. We consider the influ-

*E-mail: ss19@econ.cam.ac.uk ence of weather shocks at a disaggregated level of analysis, modelling the effects of weather on agriculture, construction and energy demand. The impact of weather shocks will vary from sector to sector as the conditions favouring one activity may be adverse to another. The extent of such dampening will also depend on changes in the sectoral structure of the economy over time. In this paper we aggregate the effect of weather by considering the largest weathersensitive sectors during this period: agriculture, construction and energy demand (which for this period results in variations in the demand for coal). In Britain, these 3 sectors accounted for approximately $25 \%$ of the gross domestic product (GDP) in the 1870 s, falling to $17 \%$ of GDP in the early 20 th century. The general approach proposed entails 2 main features: first, we model the impact of weather on sectoral production,

\footnotetext{
${ }^{1}$ Most economists dismiss Jevons' approach to economic cycles as mechanical and simplistic. In fact his theory is neither. Jevons started with the observation that it is not possible to find a solar cycle in European grain prices (Jevons 1884 , p. 231). To get a more convincing theory of the British cycle, he considered fluctuations in trade with India, where on average the sunspot cycle is correlated with periodic famines. The demand shocks in India are then transmitted to the British economy via trade links. We are most grateful to a referee of this journal for elaborating this point
} 
using the available historical sector-specific information for weather and economic data. Secondly, we aggregate the impact effect of weather shocks on the macroeconomy by aggregating the sectoral effects using a national income accounting framework. ${ }^{2}$ The choice of Britain as our case study is partly because of data availability. However, it has the added advantage that Britain's unique production structure at the end of the 19th century, with a very small agricultural sector, makes this case study relevant for our understanding of many other economies in the first half of the 20th century. It was not until the 1950s that many other European economies had a comparable sectoral production structure.

Historical analyses of the relationship between weather and the economy can help us understand the past and yield insights into how we might expect particular sectors to respond to future climatic shocks. The sectoral-climatic linkages can also help us understand the processes generating sectoral fluctuations, suggesting broader implications for modelling macroeconomic cycles. To the extent that weather shocks have an observable influence on sectoral fluctuations, real supply-side shocks should figure in sectoral business cycle behaviour. The development of modern theories of economic cycles, such as the real business cycle theory, has the potential of allowing for the importance of weather shocks as supply-side shocks to the economy. Much of the recent business cycle literature has emphasised the importance of sectoral technological shocks but has neglected the importance of weather shocks as a complementary explanation.

The paper is structured as follows: Sections 2 to 4 consider the effects of weather on agriculture, construction and coal production respectively. In considering these 3 sectors it should be emphasised that the main channel of weather influences on the agricultural and the construction sector is via supply-side shocks, whilst the effect on coal output is via variations in the demand for energy. Section 5 uses a national income accounting framework to aggregate the sum of these sectoral effects over time. This allows us to consider the macroeconomic effects of weather.

\section{WEATHER EFFECTS ON AGRICULTURAL OUTPUT}

Despite a relative decline, the British agricultural sector remained the dominant weather-sensitive sector

\footnotetext{
${ }^{2}$ It should be noted that we do not explicitly discuss the sectoral dynamics resulting from these impact effects. In terms of business cycle discussions, the focus is on impulses and not on propagation
}

of the late 19th century. The importance of weather effects on agriculture has long been recognised in the historical literature (Jones 1964, Perry 1973, Parry 1981). The adverse seasons over the period are characterised by a series of very wet summers in the 1870 s and a series of drought years in the 1890s (with more normal conditions being observed in the 1880 s and 1900s). The cool, wet summers of the 1870s implied poor harvest quantity and quality and adverse effects on livestock production and mortality; an estimated $10 \%$ of Britain's sheep population perished with liverrot (Perry 1973). Similarly the relatively extreme dry summers of the 1890s had detrimental effects both on crop production and grazing. However, although anecdotal evidence can be found in the historical literature, and in contemporary accounts, there has been little quantitative research. This is partly the result of the fact that the agricultural sector is obviously weathersensitive. However, quantifying the nature of this relationship is not a simple exercise. In particular, since high and low extremes of weather conditions are likely to have adverse effects, the weather-production relationship is expected to be non-linear. A semiparametric time-series approach will be used to model output as a linear function of economic inputs and a non-linear function of weather variables.

Semiparametric models offer an effective way of modelling non-linearity (Engle et al. 1986). Such models combine the partial linear specification in a subset of the explanatory variables $\boldsymbol{x}$, with a nonparametric specification in the remaining variable(s) $z$ :

$$
y=\mathbf{x} \beta+g(\mathbf{z})+\varepsilon
$$

where $y$ is the dependent variable; $\boldsymbol{x}$ is the $p \times 1$ vector of linear explanatory variables; $\beta$ is the coefficient matrix; $g(z)$ is the nonparametric function allowing for a non-linear relationship between $y$ and $z$; and $\varepsilon$ is a random disturbance term.

Denoting $y_{t}$ as the log of the output, $\boldsymbol{x}_{t}$ as the vector of variables, $\beta$ as the corresponding parameter vector for $\boldsymbol{x}_{t}$ and $\boldsymbol{z}_{t}$ as the vector of weather variables, we can rewrite Eq. (1) as

$$
\begin{aligned}
& y_{t}=y_{t}^{\mathrm{e}}+y_{t}^{\mathrm{w}} \\
& y_{t}^{\mathrm{e}}=\boldsymbol{x}_{t} \beta+\eta_{t}^{\mathrm{e}} \\
& y_{t}^{\mathrm{w}}=g\left(\boldsymbol{z}_{t}\right)+\eta_{t}^{\mathrm{w}}
\end{aligned}
$$

where $y_{t}^{\mathrm{e}}$ and $y_{t}^{\mathrm{w}}$ capture the effect of economic inputs and the effect of weather respectively.

The effect of weather on output is expected to be non-linear, but of unknown form. An important property of the nonparametric estimation of weather effects is that the methodology does not assume an a priori form for the dependence of the response on the explanatory variables (a fuller outline of the methodology can be found in Khatri et al. 1998). This differs from the 
Table 1. Augmented Dickey-Fuller tests for stationarity in the levels of agri cultural sector variables (1867-1913)

\begin{tabular}{|c|c|c|c|c|c|}
\hline & logOutput & logLabour & logCapital & logLand & $\begin{array}{c}\text { Critical } \\
\text { value }\end{array}$ \\
\hline \multicolumn{6}{|c|}{ Without trend } \\
\hline $\mathrm{ADF}(0)$ & $-5.27^{*}$ & -2.06 & 3.80 & -3.53 & -2.93 \\
\hline $\mathrm{ADF}(1)$ & -3.57 & -2.07 & 0.32 & -3.09 & -2.93 \\
\hline $\mathrm{ADF}(2)$ & -2.94 & -1.98 & $1.03^{*}$ & -2.90 & -2.93 \\
\hline $\operatorname{ADF}(3)$ & -3.26 & -1.94 & 1.08 & $-1.65^{*}$ & -2.93 \\
\hline $\mathrm{ADF}(4)$ & -3.04 & $-2.08^{*}$ & 0.57 & -1.24 & -2.93 \\
\hline \multicolumn{6}{|c|}{ With trend } \\
\hline $\mathrm{ADF}(0)$ & $-5.26^{*}$ & -1.87 & 0.73 & -0.76 & -3.52 \\
\hline $\mathrm{ADF}(1)$ & -3.54 & -2.79 & -0.86 & -0.97 & -3.52 \\
\hline $\mathrm{ADF}(2)$ & -2.88 & -2.38 & $-0.22^{*}$ & $-1.49^{*}$ & -3.52 \\
\hline $\mathrm{ADF}(3)$ & -3.29 & -1.53 & -0.08 & -1.09 & -3.52 \\
\hline $\mathrm{ADF}(4)$ & -3.10 & $-0.73^{*}$ & -0.33 & -1.14 & -3.52 \\
\hline
\end{tabular}

ments over long-run time periods to a handful of areas. Wigley \& Atkinson (1977) calculate growing season SMD values for Kew Gardens back to 1698.

In other work we have shown that estimation of the agro-weather production relationship for Britain gives similar results when using a variety of weather information, including soil moisture levels, annual temperature and rainfall, and growing period temperature and rainfall (Khatri et al. 1998). For simplicity of presentation, in this study we focus on the results using annual temperature and rainfall series.

The reliability of the historical data allows us to consider the sample period 1867-1913. ${ }^{3}$ Our initial aim was to fit a sectoral production function to model the

polynomial methodology in parametric methods where an a priori function is assumed.

Our aim is to estimate the magnitude of the effects of weather on agricultural output. Finding a relevant index for the weather conditions influencing the agricultural sector is not straightforward, partly because there does not exist a unique relationship between a single element of weather and agricultural production. The impact of weather on agricultural production depends on a number of factors, including rainfall, temperature, sunshine hours, soil type and wind speed (Oury 1959). Since agricultural production is an aggregate index, the selection of appropriate weather variables will be affected. Selecting only 1 element of weather might thus be considered an over-simplification. An index of agricultural drought that relates these different weather inputs may provide a good summary measure of relevant information. The effect of weather on soil moisture levels during the growing period is a key mechanism through which weather conditions affect output. A combination of precipitation and evapotranspiration (evaporation from the soil surface and transpiration from plants) will determine soil moisture levels. Evapotranspiration itself will depend on climate, soil moisture, plant cover and land management (Thornthwaite 1948, Oury 1959).

A useful practical index of weather is the soil moisture level during the growing season. Rodda et al. (1976) concludes that soil moisture deficits (SMD) provide the best practical drought index. Extreme deviations from mean soil moisture levels in either direction are thus predicted to have adverse effects on output. The most fundamental problem with this approach is the requirement of complex measurements needed to calculate the soil moisture level. Such data requirements limit the availability of soil moisture measure- effects of weather variables on output. ${ }^{4}$ To avoid the problem of spurious regression, it is necessary to determine the order of integration of the data series to be analysed. Tables 1 \& 2 report the results of augmented Dickey-Fuller (ADF) tests for trend-stationarity (a basic assumption in regression analysis) using Akaike information criterion (AIC) to determine appropriate lag lengths. For completeness, in the light of the debates on global warming, we also tested for the stationarity of the relevant weather variables (in this case annual temperature and rainfall). All the weather variables are found to be level stationary over this sample period. ${ }^{5}$

While agricultural output and weather variables are stationary in levels, the series for labour, capital and land inputs are not. The ADF tests suggest that capital stock and land might not be stationary even in first differences. However, within a fractional framework, Table 3 shows that the estimated fractional differencing orders of $\Delta \log C a p i t a l$ and $\Delta \log L a n d$ are not significantly different from zero using the approach of Sowell (1992). Labour, capital stock and land inputs are all integrated of order 1.

Such a structure to the time series data prevents us from working within a basic production function

\footnotetext{
${ }^{3}$ Although Feinstein (1972) presents a series for annual agricultural production since 1855, for the period 1855-66 this is constructed from indicator information, which may not capture annual fluctuations. The data are described in the Appendix 1

${ }^{4} \mathrm{An}$ alternative route is to use duality theory (Chambers 1988) and estimate a cost function for the sector. However, data availability for the late 19th century prevented us from following this route. The only major component of the cost function that could be documented over time is the cost of agricultural labour in the form of agricultural wage data

${ }^{5}$ The results are not reported here but are available in a longer version of this paper upon request from the authors
} 

of agricultural sector variables (1868-1913)

\begin{tabular}{|c|c|c|c|c|c|}
\hline & $\Delta \log O u t p u t$ & $\Delta \log L a b o u r$ & $\Delta \log$ Capital & $\Delta \log L a n d$ & $\begin{array}{l}\text { Critical } \\
\text { Value }\end{array}$ \\
\hline \multicolumn{6}{|c|}{ Without trend } \\
\hline $\operatorname{ADF}(0)$ & -10.83 & -4.87 & -1.69 & -4.57 & -2.93 \\
\hline $\mathrm{ADF}(1)$ & $-7.17^{*}$ & -4.59 & $-2.22^{*}$ & -3.32 & -2.93 \\
\hline $\operatorname{ADF}(2)$ & -4.54 & -4.90 & -1.89 & $-2.02^{*}$ & -2.93 \\
\hline $\mathrm{ADF}(3)$ & -4.15 & $-5.25^{*}$ & -1.26 & -2.07 & -2.93 \\
\hline $\mathrm{ADF}(4)$ & -4.65 & -4.06 & -0.87 & -2.05 & -2.93 \\
\hline \multicolumn{6}{|c|}{ With trend } \\
\hline $\operatorname{ADF}(0)$ & -10.68 & -5.08 & -2.82 & -7.33 & -3.52 \\
\hline $\operatorname{ADF}(1)$ & $-7.07^{*}$ & -4.88 & $-3.76^{*}$ & -6.74 & -3.52 \\
\hline $\operatorname{ADF}(2)$ & -4.69 & -5.30 & -3.48 & $-3.75^{*}$ & -3.52 \\
\hline $\mathrm{ADF}(3)$ & -4.08 & $-5.83^{*}$ & -2.72 & -3.64 & -3.52 \\
\hline $\operatorname{ADF}(4)$ & -4.61 & -4.73 & -2.27 & -3.69 & -3.52 \\
\hline
\end{tabular}

Table 2. Augmented Dickey-Fuller tests for stationarity in the growth rates

weather variables. The model allows for autocorrelation in agricultural growth rates, reflecting cycles in the sector's growth rate. Both weather variables are statistically significant and have nonlinear effects on output (see the non-parametric F-test reported in Table 4). The shape of the estimated non-linear effect of annual temperature and rainfall on the output growth rate is plotted in Fig. 1a,b. Variations in the growth rate of economic inputs are all insignificant. ${ }^{6}$ The model accounts for $69 \%$ of the variance (i.e. the null deviance for the model with a Gaussian distribution) in the growth of agricultural output, with the weather variables accounting for $45 \%$ of the variance in the growth of agricultural output. The total impact of the weather variables on agri-

framework. All the results so far suggest that to proceed to estimating a production function would generate spurious statistical results. However, the results suggest that the growth rates of all the economic series are stationary series, allowing us to estimate the effects of weather on the growth of agricultural output, controlling for the growth of factor inputs. Thus, weather is being evaluated as a shock that explains fluctuations in the growth rate of output. Although this procedure leads to a loss of information, there is a gain in terms of data reliability. For example, given the methods by which historical data have been constructed (which rely heavily on methods of extrapolation and interpolation), growth rates are measured more accurately than their levels (Solomou \& Weale 1993). We estimate the following model:

$$
\begin{aligned}
\Delta \log \text { Output }_{t}= & \beta_{0}+\beta_{1} \Delta \log \text { Labour }_{t}+\beta_{2} \Delta \log \text { Capital }_{t}+ \\
& \beta_{3} \Delta \operatorname{logLand} t+g\left(\boldsymbol{z}_{t}\right)+h_{t}
\end{aligned}
$$

where the growth of agricultural output is a linear function of the growth rates of labour, capital and land inputs and a non-linear function of weather variables.

Table 4 reports the results for the semiparametric model using annual temperature and rainfall as the

\footnotetext{
${ }^{6}$ For the post World War II period using a cost function approach to estimate the effects of weather on agricultural output and inputs, it has been suggested that weather is not significantly correlated with inputs (Khatri \& Solomou 1995). Hence, the results for weather effects on output are unlikely to be biased by a collinearity with economic inputs ${ }^{7}$ Since weather variables are cyclical, we also experimented with models that use the cyclical components of weather data in the estimation. The cyclical components were derived using the wavelet decomposition method. The general structure of the results is comparable to the results reported in this paper. A full version of the wavelet results can be obtained from the authors
} cultural output is plotted in Fig. $2 .^{7}$

Fig. 2 shows the actual fluctuations of the growth of agricultural output together with the estimated total weather effect (i.e. the combined temperature and rainfall effect on production). The weather effect on

Table 3. Integration order test within fractional framework $\operatorname{ARFIMA}(p, d, 0)$ models. $\operatorname{ARFIMA}(p, d, 0)=$ fractionally integrated autoregressive moving average model with autoregressive order $=p$, moving average order $=0$ and fractional order $=d$. $p$ is the order suggested by the AIC. $t$-statistics are given in parenthesis

\begin{tabular}{|ccc|}
\hline & $\Delta \log$ Capital & $\Delta \log$ Land \\
\hline$p$ & 1 & 3 \\
$d$ & 0.28 & -0.14 \\
& $(1.45)$ & $(-0.86)$ \\
\hline
\end{tabular}

Table 4. Semiparametric model for agricultural growth (1868-1913). $\operatorname{Pr}(>|t|)$ and $\operatorname{Pr}(F)$ represent the statistical significance levels of $t$-tests for the parametric part of the model and $F$-tests for the variables estimated in the nonparameteric part of the estimation. All the semiparametric estimations were made using S-Plus

\begin{tabular}{|lcc|}
\hline Parametric part & $t$-ratio & $\operatorname{Pr}(>|t|)$ \\
$\Delta$ logOutput (lagged) & -4.28 & 0.01 \\
Nonparametric part & Npar $F$ & $\operatorname{Pr}(F)$ \\
$S($ Temperature, 4) & 10.30 & 0.01 \\
$S($ Rainfall, 3) & 3.85 & 0.02 \\
a $S$ (Temperature, 4) is defined as the non-parametric \\
smoothing function of temperature estimated with 4 \\
degrees of freedom (see Fig. 1a). The degrees of freedom \\
determine the shape of the response function (see \\
Fig. 1a). The optimal number of degrees of freedom is \\
chosen using the AIC on the best fit of the model. This is \\
also the case for $S($ Rainfall, 3), illustrated in Fig. 1b
\end{tabular}



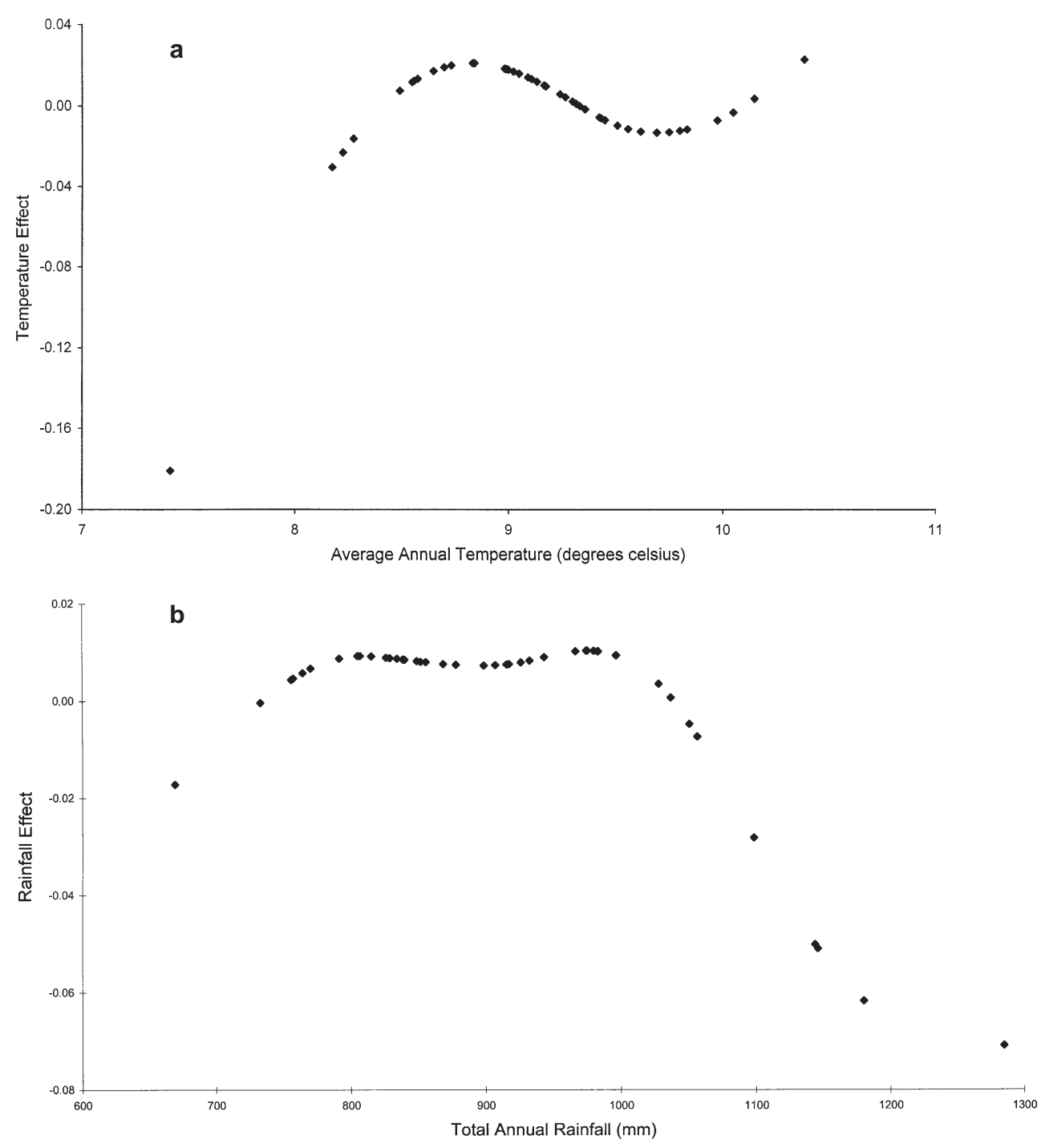

Fig. 1. (a) Temperature and (b) rainfall effect on agricultural growth output

agricultural production growth ranges from -17 to $+3 \%$. Over time the effect of weather on output growth is not trended, although the effect is wider in some years of the 1870s than for the period 1880-1913.

The econometric results reported here are consistent with data from the Rothamsted agricultural experimental station, which show that during the late Victorian period as much as 60 to $70 \%$ of the variation in crop yields can be explained by weather. Given that crop output is likely to be more weather sensitive than animal production, we would expect total agricultural production not to be as sensitive as for crop production. Thus, for aggregate agricultural production we find that weather effects can account for approximately $50 \%$ of the variance in aggregate agricultural output.

\section{WEATHER EFFECTS ON CONSTRUCTION}

During the pre-1913 period, although the construction sector accounted for less than $5 \%$ of the GDP, the sector played a key role in the cyclical adjustments of the British economy (Thomas 1973, Feinstein et al. 1982, Solomou 1987). Our aim is to evaluate the extent to which weather shocks provide a measurable supplyside shock at a sectoral level and to document the magnitudes of the effect on construction sector output. Construction is recognised as being a weathersensitive sector; since building work is to a large extent undertaken on open sites, it is subject to the effects of weather variations (Jones 1964, Russo 1966, Maunder 1986, Prior 1989). For example, during the 19th century almost the whole annual production of bricks took 


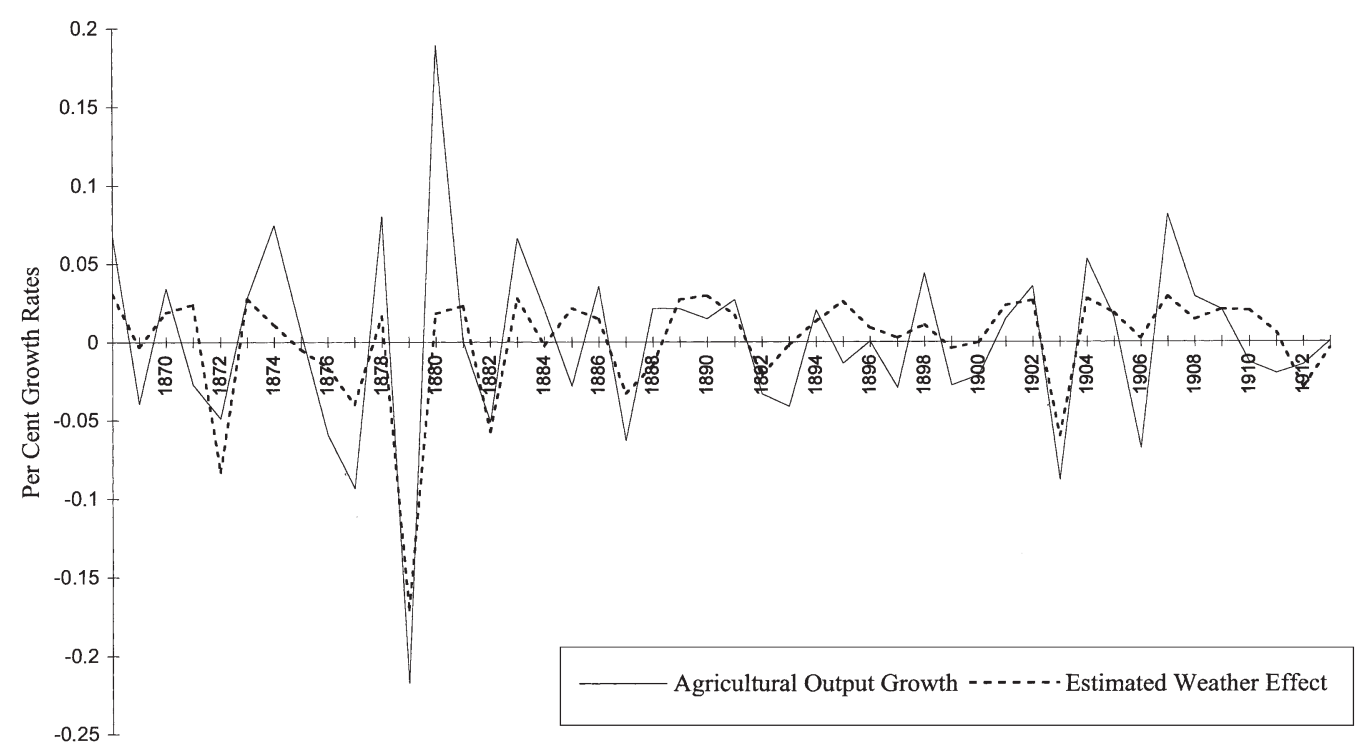

Fig. 2. Agricultural output growth and estimated weather effect

place between April and September, when weather conditions were favourable (Jones 1964).

A number of weather conditions will affect the sector: for example, extremes of rain and temperature and hard frosts. As noted in Appendix 1, we experimented with models that used high-frequency weather data to explain annual economic data; however, the best fitting models were those that related annual economic data to annual weather data. We also found total frost days over the year to have a statistically insignificant effect on construction growth. Hence, the models reported in this paper use annual rainfall and temperature weather data. Because both high and low extremes of weather conditions are likely to have adverse effects, the general specification of a weatherproduction relationship we estimate is non-linear. The data sources for construction sector output, labour input and weather are described in Appendix $1 .^{8}$ Tables 5 \& 6 present the ADF statistics of the economic variables and their first-order differences respectively. The results suggest that construction sector output and labour input are integrated of order 1. As noted above annual rainfall and temperature series for this period are stationary series.

Since construction output and labour input (expressed as logs) are integrated of the same order (order 1), we use the statistical method of co-integra-

\footnotetext{
${ }^{8}$ We use data for the sample period 1855-1913 when estimating the sectoral model

${ }^{9}$ Although single-step estimation is optimal, we follow the 2step procedure here as a pragmatic procedure, allowing us to focus on the semiparametric estimates of weather effects
}

tion to evaluate the existence of a long-run equilibrium relationship between these 2 variables. Construction output and labour input are bounded together by a long-run equilibrium relationship:

$$
\log \text { Output }_{t}=\alpha_{0}+\alpha_{1} t+\alpha_{2} \log \text { Labour }_{t}+e_{t}
$$

where $t$ is a linear time trend. The residuals from this model are trend stationary. Within the error correction framework, ${ }^{9}$ the lagged residuals $\left(e_{t-1}\right)$ from this regression can be used to estimate the error-correction model:

$$
\text { slogOutput }_{t}=\beta_{0}+\beta_{1} \Delta \log \text { Labour }_{t}+\beta_{2} e_{t-1}+h_{t}
$$

Since the weather variables are stationary, we can include a vector of weather variables, $\boldsymbol{z}_{t}$ and analyse the weather effect on the construction growth rate:

Table 5. Augmented Dickey-Fuller tests for stationarity in the levels of construction sector variables (1855-1913)

\begin{tabular}{|llll|}
\hline & logOutput & $\log$ Labour & Critical values \\
\hline Without trend & & & \\
ADF(0) & -2.34 & -1.47 & -2.92 \\
ADF(1) & $-2.09^{*}$ & $-1.13^{*}$ & -2.92 \\
ADF(2) & -2.08 & -1.13 & -2.92 \\
ADF(3) & -2.15 & -1.19 & -2.92 \\
ADF(4) & -2.15 & -1.16 & -2.92 \\
With trend & & & \\
ADF(0) & -1.20 & -1.07 & -3.49 \\
ADF(1) & $-2.27^{*}$ & $-2.22^{*}$ & -3.49 \\
ADF(2) & -2.43 & -1.85 & -3.49 \\
ADF(3) & -2.89 & -1.42 & -3.49 \\
ADF(4) & -3.16 & -1.59 & -3.49 \\
${ }^{*}$ Lag length suggested by AIC & \\
\hline
\end{tabular}


$\Delta \log$ Output $_{t}=\beta_{0}+\beta_{1} \Delta \log$ Labour $_{t}+\beta_{2} e_{t-1}+g\left(z_{t}\right)+h_{t}$

This model explains the growth rate of construction output in terms of responses to changes in labour input and adjustment to equilibrium levels (as captured by the $e_{t-1}$ variable) and weather fluctuations, which is the focus of this paper. Table 7 reports the results of estimating this semiparametric model. The estimation also allows for autocorrelation in the dependent variable, capturing cycles in construction sector growth. Although the estimation method is non-parametric and is capable of capturing non-linear effects, temperature and rainfall are found to have a linear effect on construction output. ${ }^{10} \mathrm{~A}$ joint variable deletion test on both weather variables suggests that they are statistically significant at the $5 \%$ level, although individually the rainfall effect is only significant at the $7 \%$ level and temperature at the $10 \%$ level. The model explains $51 \%$ of the observed variations in the growth rate of construction sector output, with weather accounting for $6 \%$ of the total. Clearly, although the construction sector is weather-sensitive, most of this dependence is observed in high-frequency seasonal fluctuations (Solomou \& Wu 1997); at the annual frequency weather only accounts for a small proportion of the sector's fluctuations, suggesting that much of the dis-

Table 6. Augmented Dickey-Fuller tests for stationarity in the growth rates of construction sector variables (1856-1913)

\begin{tabular}{|c|c|c|c|}
\hline & $\Delta \log O u t p u t$ & $\Delta \log L a b o u r$ & Critical values \\
\hline \multicolumn{4}{|c|}{ Without trend } \\
\hline $\operatorname{ADF}(0)$ & $-4.00^{*}$ & $-4.70^{*}$ & -2.92 \\
\hline $\mathrm{ADF}(1)$ & -3.41 & -4.70 & -2.92 \\
\hline $\mathrm{ADF}(2)$ & -2.72 & -4.55 & -2.92 \\
\hline $\mathrm{ADF}(3)$ & -2.57 & -3.65 & -2.92 \\
\hline $\operatorname{ADF}(4)$ & -3.08 & -2.77 & -2.92 \\
\hline \multicolumn{4}{|c|}{ With trend } \\
\hline $\mathrm{ADF}(0)$ & $-4.12^{*}$ & -4.73 & -3.50 \\
\hline $\mathrm{ADF}(1)$ & -3.53 & $-4.78^{*}$ & -3.50 \\
\hline $\mathrm{ADF}(2)$ & -2.84 & -4.68 & -3.50 \\
\hline $\mathrm{ADF}(3)$ & -2.71 & -3.79 & -3.50 \\
\hline $\mathrm{ADF}(4)$ & -3.29 & -2.89 & -3.50 \\
\hline
\end{tabular}

Table 7. Model of growth of new building construction output (1856-1913)

\begin{tabular}{|lrc|}
\hline Parametric part & $t$-ratio & $\operatorname{Pr}(>|t|)$ \\
\hline Lag $\Delta$ logOutput & 4.25 & 0.01 \\
AlogLabour & 3.07 & 0.01 \\
Lag of ECM & -3.18 & 0.01 \\
Temperature & 1.67 & 0.10 \\
Rainfall & 1.83 & 0.07 \\
\hline
\end{tabular}

rupted seasonal work was able to be completed within the year.

These weather effects are plotted in Fig. 3a,b. The temperature effect range is positively correlated with output and varies from 2.6 to $-3.2 \% \mathrm{yr}^{-1}$ around the mean. The effect of annual total rainfall is linear, and negatively correlated with the growth of output. The effect range varies from 2.2 to $-3.4 \% \mathrm{yr}^{-1}$ around the mean.

Fig. 4 plots the actual growth variations of new building in Britain together with the estimated total weather effect on these growth fluctuations. Clearly, most of the observed annual fluctuations are not determined by weather effects, even though the sector is found to be weather-sensitive at the annual frequency.

\section{WEATHER EFFECTS ON ENERGY DEMAND}

Energy demand, which in the 19th century generally meant coal demand, ${ }^{11}$ is recognised to be very weather-sensitive. A number of investigators (Dryar 1949, Stephens 1951, Davies 1960, Harris 1964, Nye 1965, Engle et al. 1986, Hsiao et al. 1989, Elkhafif 1996) have documented significant weather effects on energy demand in the post-war period. Most studies consider the effect of a single weather variable. For example, Engle et al. (1986) considered variations in temperature. However, other weather conditions, such as precipitation, will also cause considerable variations in energy demand. Using an extended semiparametric model, we consider the effects of multivariate weather shocks on British coal demand. The hypothesis we consider is that coal usage would be sensitive to variations in the cold period of the year, which we approximate as the period from October to April inclusive. ${ }^{12}$

Since we wish to focus on national weather effects on coal demand, we explain variations in coal production minus exports of coal (as a measure of British consumption). Coal demand is assumed to depend on: industrial production, as a proxy of industrial demand; real wages, to capture the income effect on consumer demand for coal; and the price of energy (the data are described in Appendix 1). Stationarity tests suggest that, while real wages and energy prices follow a ran-

\footnotetext{
${ }^{10}$ During the period $1855-1913$ the correlation between annual rainfall and temperature is 0.06 , suggesting that the variables are having an independent effect on construction output

${ }^{11}$ Although gas production accounted for a growing proportion of market share at the end of the 19th century, gas was produced from coal burning

${ }^{12}$ We also considered annual weather information. However, variations over the cold period are a better explanatory variable
} 

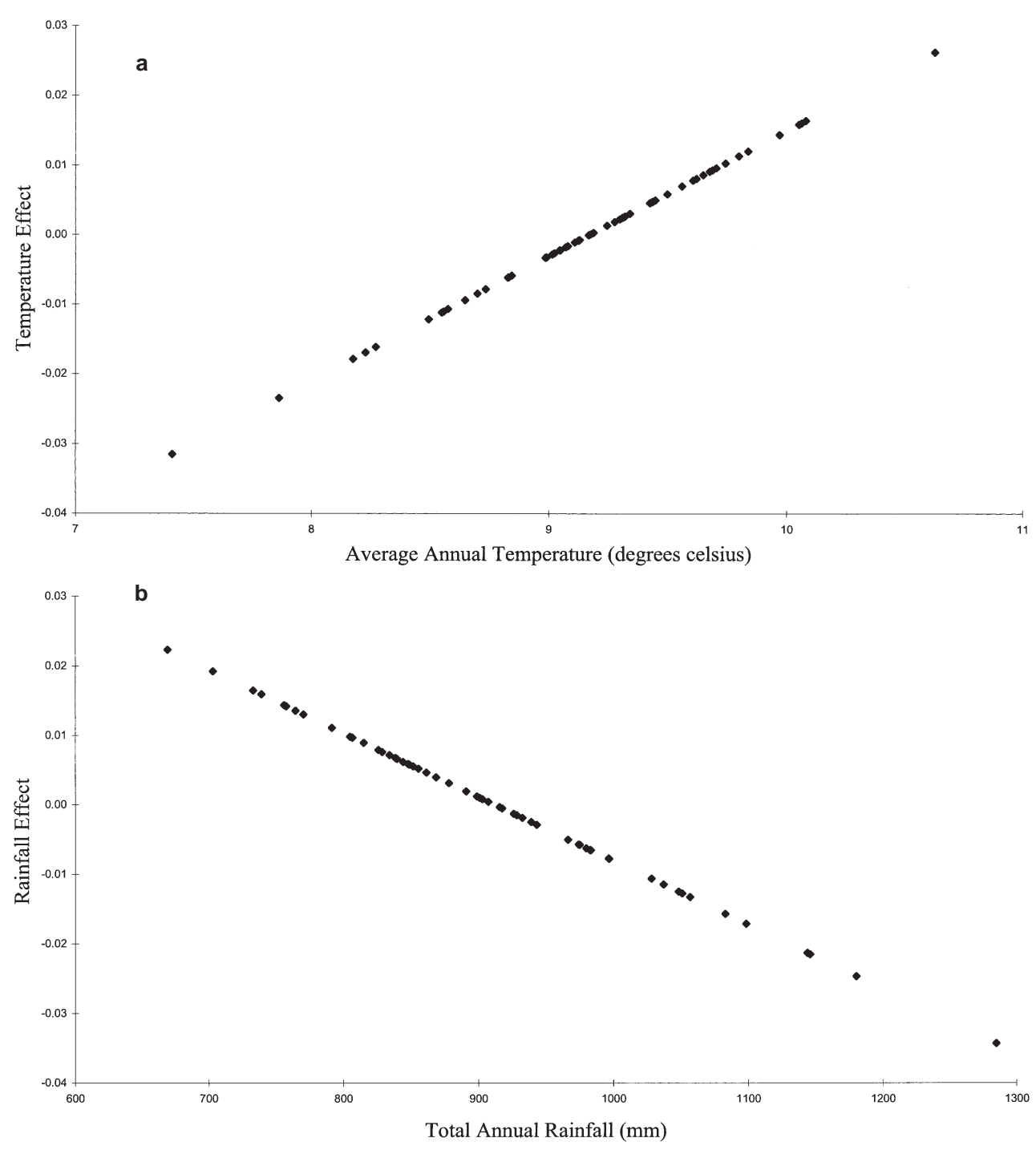

Fig. 3. (a) Temperature and (b) rainfall effect on construction output growth

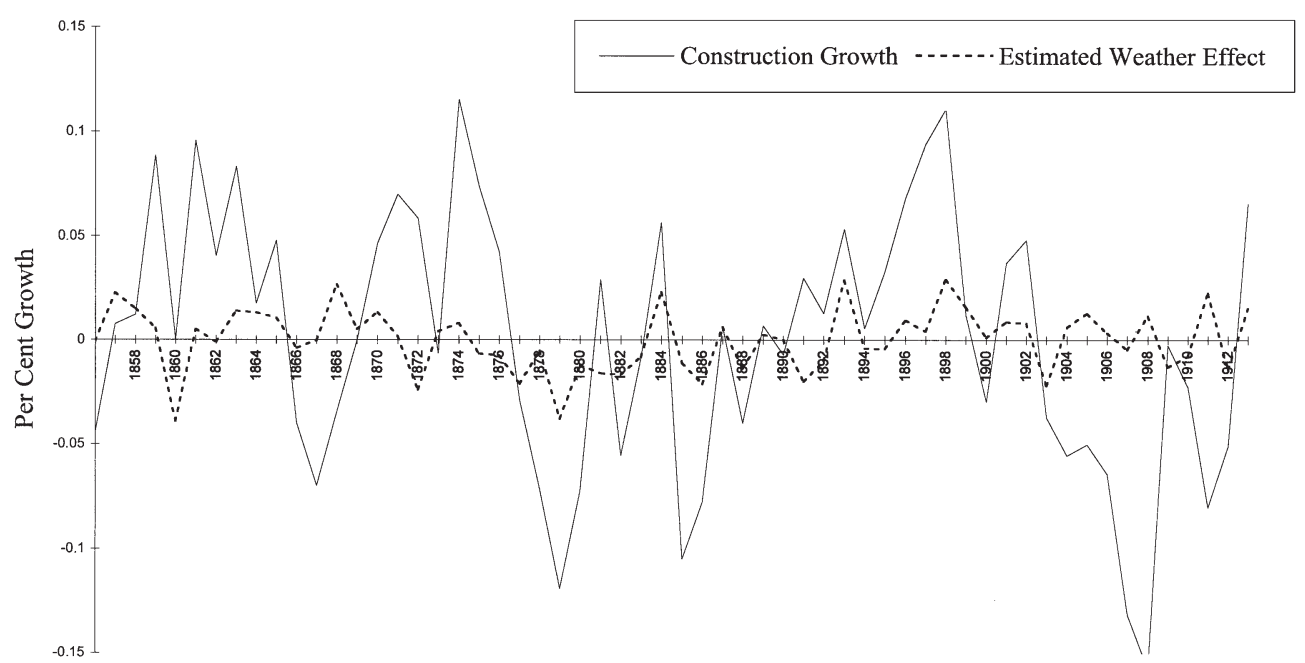

Fig. 4. Construction output growth and estimated weather effect 
dom walk, coal consumption and industrial production are trend-stationary (see Tables 8 \& 9). Given the low power of unit root tests, we also investigate the trend stationarity of coal consumption and industrial production further, employing the fractional framework (Sowell 1992). This suggests that the series are not clearly trend-stationary. The estimated fractional differencing orders for coal consumption and industrial production are significantly different from zero (see Table 10). Working with the assumption that the series are all non-trend-stationary, we consider whether there exists a co-integrating relationship between these variables. The Johansen methodology suggests that there exists 1 cointegrating vector.

Given the properties of the series, the error correction methodology is used to estimate the growth of coal consumption in terms of the following model:

Table 8. Augmented Dickey-Fuller tests for stationarity in the levels of coal sector (1870-1913)

\begin{tabular}{|llllll|}
\hline \multicolumn{2}{|c}{$\begin{array}{c}\text { logCoal } \\
\text { consumption }\end{array}$} & $\begin{array}{c}\text { logIndustrial } \\
\text { production }\end{array}$ & $\begin{array}{c}\text { logReal } \\
\text { wages }\end{array}$ & $\begin{array}{c}\text { logPrice } \\
\text { of coal }\end{array}$ & $\begin{array}{c}\text { Critical } \\
\text { values }\end{array}$ \\
\hline Without trend & & & & \\
$\mathrm{ADF}(0)$ & -0.80 & -0.11 & 2.46 & $-2.80^{*}$ & -2.94 \\
$\mathrm{ADF}(1)$ & $-0.73^{*}$ & -0.29 & 1.55 & -2.75 & -2.94 \\
$\mathrm{ADF}(2)$ & -0.69 & -0.18 & 1.57 & -2.67 & -2.94 \\
$\mathrm{ADF}(3)$ & -0.68 & -0.07 & $1.78^{*}$ & -2.78 & -2.94 \\
$\mathrm{ADF}(4)$ & -0.76 & $-0.15^{*}$ & 1.87 & -2.81 & -2.94 \\
With trend & & & & & \\
$\mathrm{ADF}(0)$ & $-4.19^{*}$ & -2.70 & -2.21 & $-2.57^{*}$ & -3.53 \\
$\mathrm{ADF}(1)$ & -3.65 & -4.37 & $-2.56^{*}$ & -2.53 & -3.53 \\
$\mathrm{ADF}(2)$ & -3.71 & $-4.66^{*}$ & -2.46 & -2.38 & -3.53 \\
$\mathrm{ADF}(3)$ & -3.92 & -2.96 & -1.71 & -2.45 & -3.53 \\
$\mathrm{ADF}(4)$ & -3.44 & -2.54 & -1.55 & -2.40 & -3.53 \\
${ }^{*} \mathrm{Lag}$ length suggested by AIC & & & \\
\hline
\end{tabular}

Table 9. Augmented Dickey-Fuller tests for stationarity in the growth rates of coal sector (1871-1913)

\begin{tabular}{|lcclll|}
\hline \multicolumn{2}{|c}{$\begin{array}{c}\text { logCoal } \\
\text { consumption }\end{array}$} & $\begin{array}{c}\text { logIndustrial } \\
\text { production }\end{array}$ & $\begin{array}{c}\text { logReal } \\
\text { wages }\end{array}$ & $\begin{array}{c}\text { logPrice } \\
\text { of coal }\end{array}$ & $\begin{array}{c}\text { Critical } \\
\text { values }\end{array}$ \\
\hline Without trend & & & & \\
$\mathrm{ADF}(0)$ & $-7.69^{*}$ & -4.36 & -3.31 & $-5.84^{*}$ & -2.94 \\
$\mathrm{ADF}(1)$ & -5.44 & -4.06 & -2.93 & -4.64 & -2.94 \\
$\mathrm{ADF}(2)$ & -4.52 & -5.78 & $-3.63^{*}$ & -3.20 & -2.94 \\
$\mathrm{ADF}(3)$ & -4.71 & -5.03 & -3.36 & -2.77 & -2.94 \\
$\mathrm{ADF}(4)$ & -4.45 & $-4.87^{*}$ & -3.17 & -2.82 & -2.94 \\
With trend & & & & & \\
$\mathrm{ADF}(0)$ & $-7.55^{*}$ & -4.31 & -4.16 & $-6.11^{*}$ & -3.53 \\
$\mathrm{ADF}(1)$ & -5.36 & -4.01 & -3.88 & -5.05 & -3.53 \\
$\mathrm{ADF}(2)$ & -4.46 & -5.70 & $-4.48^{*}$ & -3.60 & -3.53 \\
$\mathrm{ADF}(3)$ & -4.64 & -4.95 & -4.20 & -3.22 & -3.53 \\
$\mathrm{ADF}(4)$ & -4.39 & $-4.77^{*}$ & -4.09 & -3.38 & -3.53 \\
${ }^{*} \mathrm{Lag}$ length suggested by AIC & & & \\
\hline
\end{tabular}

Table 10. Integration order test within fractional framework $\operatorname{ARFIMA}(p, d, 0) . t$-statistics in parentheses

\begin{tabular}{|ccc|}
\hline & $\Delta \log$ Coal consumption & $\Delta$ logIndustrial production \\
\hline$p$ & 0 & 3 \\
$d$ & -0.49 & -0.50 \\
& $(-3.20)$ & $(-2.20)$ \\
\hline
\end{tabular}

$\Delta \log \mathrm{Coal}_{t}=\beta_{0}+\beta_{1} \Delta \log$ Industrial production ${ }_{t}+\beta_{2} \operatorname{lag} \Delta \log \mathrm{Coal}_{t}+$ $\beta_{3} \Delta \log$ Price $_{t}+\beta_{4} e_{t-1}+g\left(z_{t}\right)+h_{t}$

The results are reported in Table 11. All the economic variables are significant and have the expected sign. The weather variables are found to be linear, although the estimation method is capable of modelling non-linear effects. ${ }^{13}$ Temperature has a negative relationship with coal demand with an effect range mostly within \pm 0.02 (see Fig. 5a). The rainfall effect is found to be positive with an effect range mostly within \pm 0.02 (see Fig. 5b). The model explains $65 \%$ of the domestic coal consumption, with the weather variables accounting for $15 \%$ of the variance.

Fig. 6 plots the actual growth rate of the domestic demand for coal and the estimated total weather effect. Clearly, a significant proportion of the total variation of the growth in coal demand is the result of business cycle effects and is not the result of weather fluctuations. Nevertheless, weather adds significant explanatory power.

\section{AGGREGATE WEATHER EFFECTS}

Weather shocks were important to the observed fluctuations of each of these 3 sectors. The effect range of weather shocks on the growth rates of construction and domestic demand for coal was around \pm 0.03 during the period 1870-1913. A slightly higher range is observed for the agricultural sector during 1880-1913, although the effect of weather was significantly wider during the 1870 s. Whether these sector-specific effects had a significant effect on the macro-economy will depend on 2 features: first, the pattern of covariance of effects across different sectors and, second, the relative weight of the different sectors in the macro-economy and changes in these shares over time. 

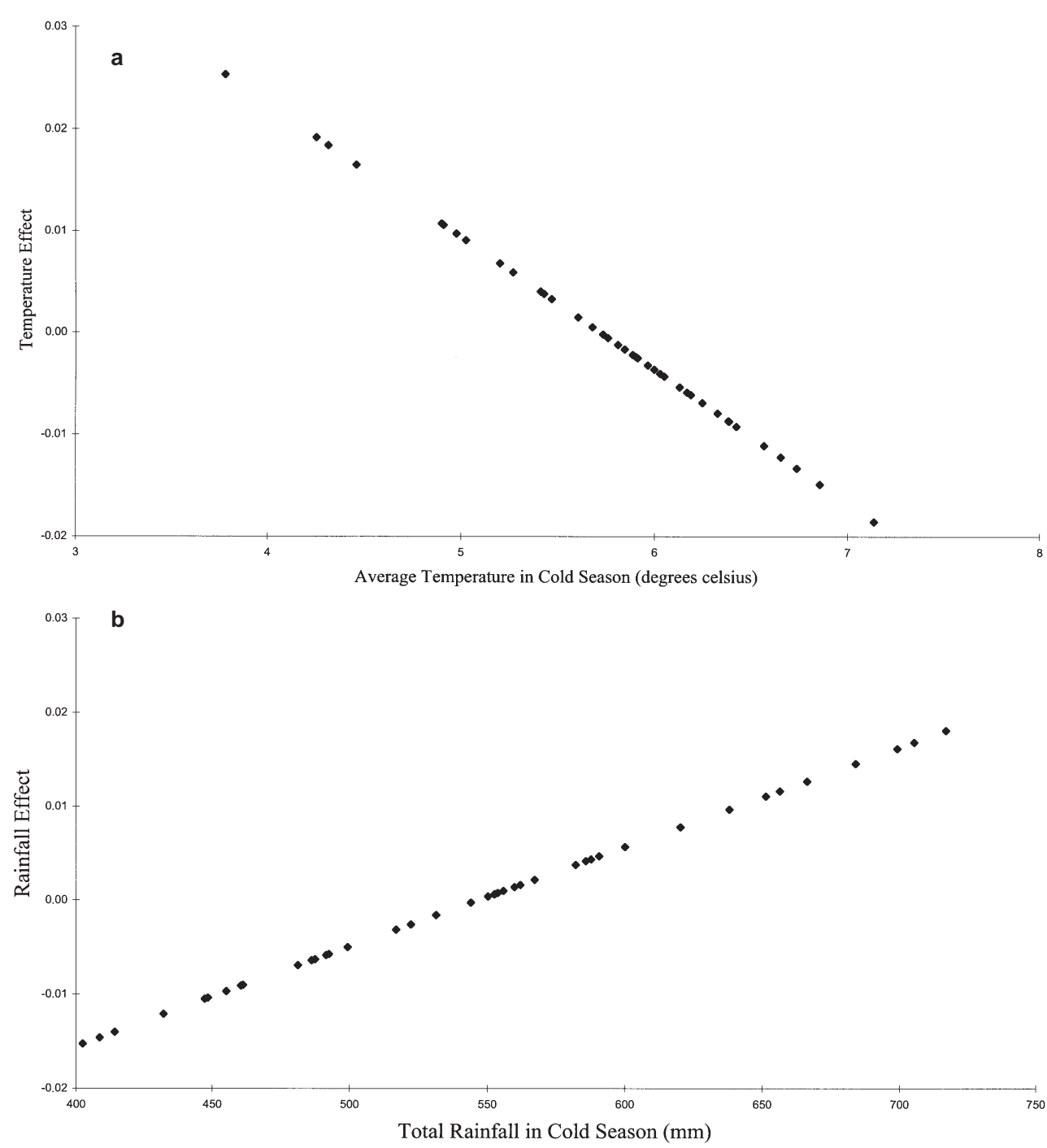

Fig. 5. (a) Temperature and (b) rainfall effect on growth of coal demand for home market

To address the first point, we consider the pattern of correlation of weather effects on different sectors. The only statistically significant correlation is a positive correlation between agriculture and construction sector effects $(r=0.51) .{ }^{14}$ There is no evidence that weather shocks were having a neutral effect on the macro-economy because adverse shocks to one sector were consistently being compensated by favourable

\footnotetext{
${ }^{13}$ The estimation sample neglects 1 data point for rainfall. During the cold period of 1893-4 the level of rain was $>800 \mathrm{~mm}$. Including this extreme observation suggests that the best fitting model is non-linear. However, the estimated relationship suggests that heavy rain reduces coal demand. Given that non-linearity depends on 1 observation, the linear specification offers a more robust description of the data ${ }^{14}$ The correlation coefficients for construction/coal and agriculture/coal are -0.14 and 0.001 respectively
}

effects to other sectors. The absence of significant negative correlations suggests that weather shocks resulted in aggregate effects over this period.

In order to evaluate the sum of all these sectoral effects we aggregate the observed sectoral shocks using

Table 11. Semiparametric model for coal with reported weather indices (1871-1913)

\begin{tabular}{|c|c|c|}
\hline Parametric part & $t$-ratio & $\operatorname{Pr}(>|t|)$ \\
\hline$\Delta \operatorname{logIndustrial~production}$ & 6.29 & 0.01 \\
\hline Lag $\Delta \log$ Coal consumption & -4.27 & 0.01 \\
\hline Lag $\Delta \log P r i c e$ & -2.45 & 0.02 \\
\hline Lag EC & -4.09 & 0.01 \\
\hline Temperature & -2.37 & 0.02 \\
\hline Rain & 3.93 & 0.01 \\
\hline
\end{tabular}




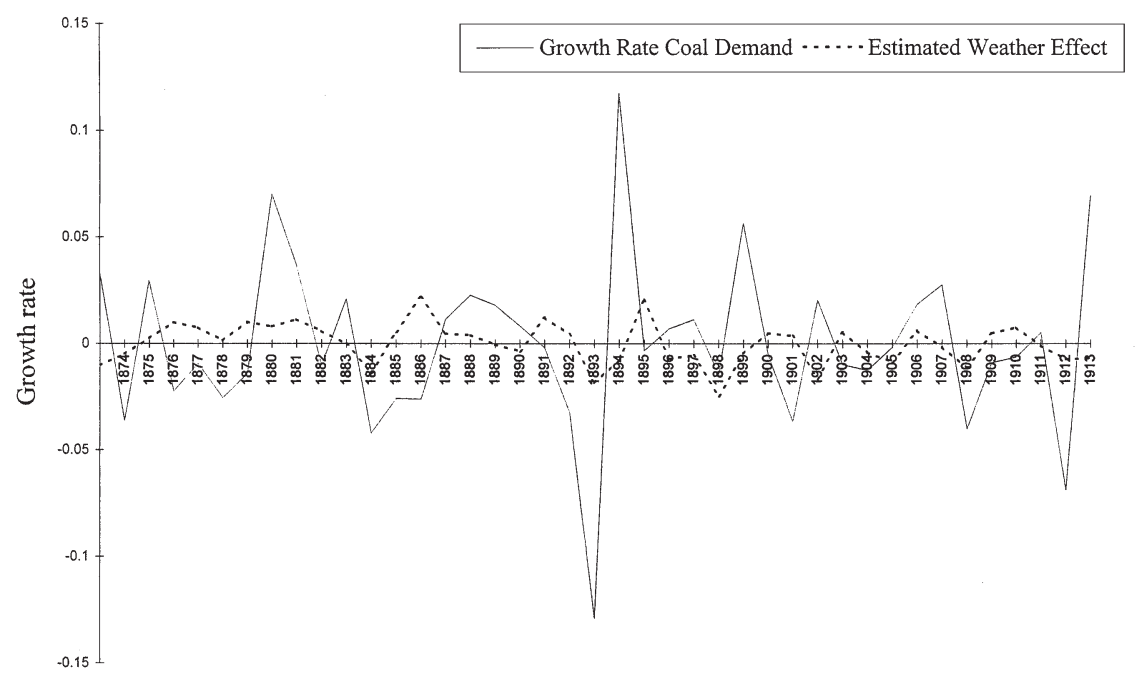

Fig. 6. Growth rate of coal demand and estimated weather effect

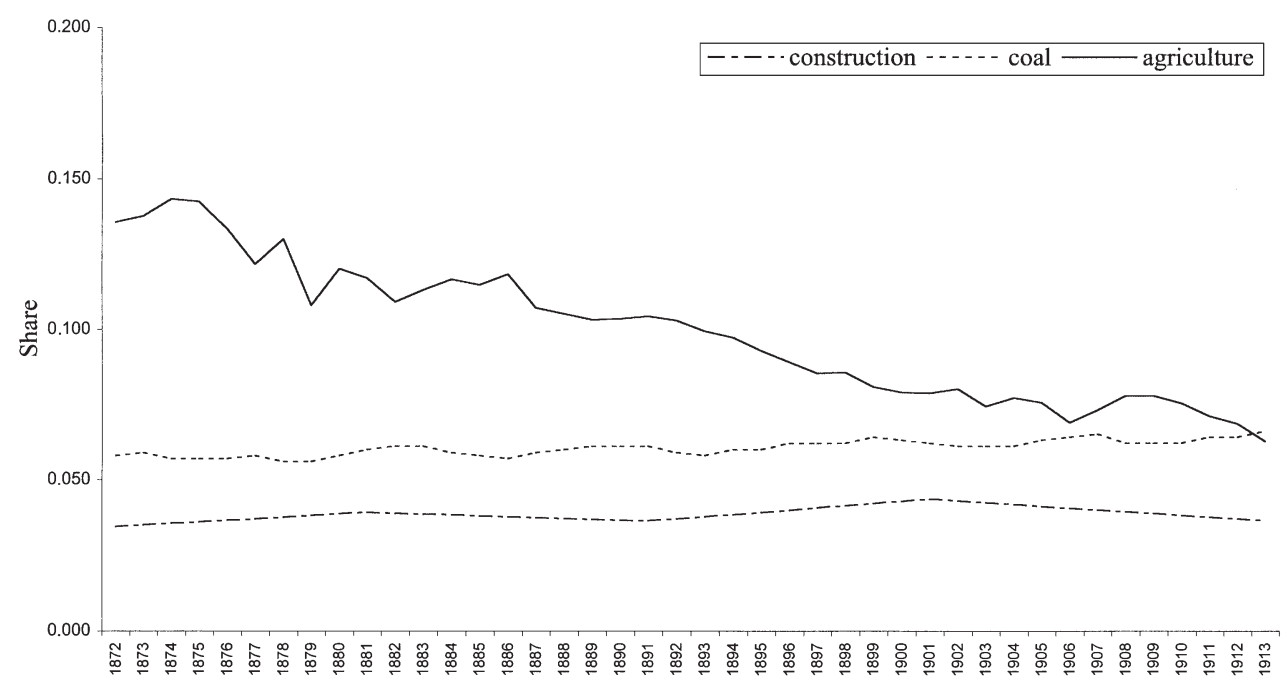

Fig. 7. Sectoral output shares in gross domestic product

GDP shares as weights. Fig. 7 plots the shares of the 3 sectors in GDP. The agricultural sector was dominant in determining the weather effect on the macro-economy. This arose because of 3 factors: first, the relative size of the agricultural sector during this period was much larger than any other major weather-sensitive sector; second, a pattern of positive co-movement between the weather effects affecting agriculture and construction reinforced them; finally, the effect range of weather shocks to agriculture was wider than the other sectors. Fig. 8 illustrates this result with a plot of the aggregateweighted weather effect and the weighted sectoral effect from agriculture. It is clear that throughout this period the total weather effect on the macro-economy is dominated by the effect of agriculture.

\section{CONCLUSIONS}

Each of the 3 sectors considered here are found to be weather-sensitive during the pre-1914 period. Weather effects on agricultural production are non-linear (with conditions of drought and excessive moisture having adverse effects) and asymmetric (with conditions of excessive moisture having larger impacts than conditions of drought). The econometric results reported here are consistent with data from the Rothamsted agricultural experimental station, which show that during this period as much as 60 to $70 \%$ of the variance in crop yields can be accounted for by weather variations. Given that crop output is likely to be more weather-sensitive than animal production, we would expect total agricultural 


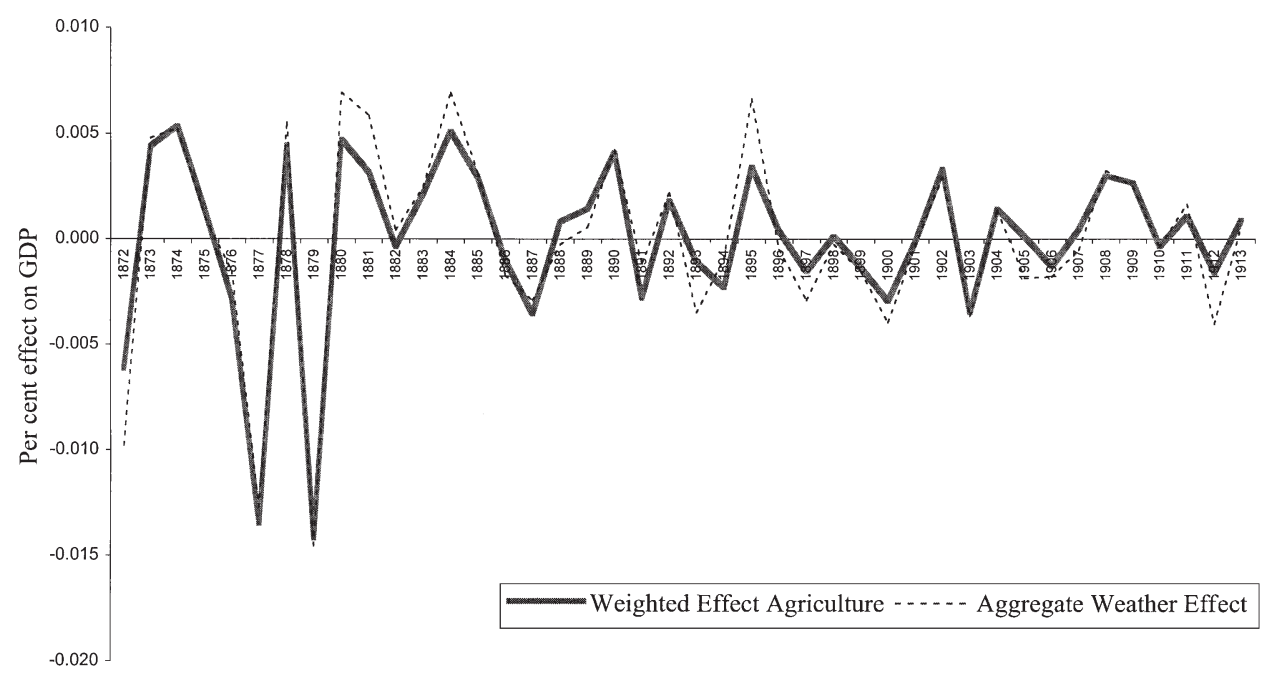

Fig. 8. Aggregate weather effect and weighted effect from agriculture

production not to be as sensitive as for crop production. Thus, for aggregate agricultural production we find that weather effects can account for ca. $50 \%$ of the variance in the growth of aggregate agricultural output. The annual weather sensitivity of the other 2 sectors is less than agriculture. Only $6 \%$ of the annual growth rate variations of construction sector output are explained by weather shocks. In the case of coal demand, weather shocks explain $15 \%$ of the variations in the growth of domestic coal demand. Given the magnitude of these different sectoral weather sensitivities and the relatively larger size of the agricultural sector, the agro-weather relationship dominates the macroeconomic impacts of weather.

Aggregating sectoral weather effects using GDP shares as weights suggests that the impact of weather shocks was significant in magnitude throughout this period. The effective range of the sum of the sectoral shocks to GDP is +0.7 to $-1.5 \%$ of the GDP. There is also some evidence that the variance of the total weighted effect declined over time; over the periods 1872-1890 and 1890-1913 the standard deviation of the total weighted effect was halved from 0.06 to 0.03 . This mainly reflects the declining share of agriculture over time. Clearly, even at the peak of industrialisation at the end of the 19th century, weather remained an important influence on modern economies. The implications for business cycle research should also be made explicit. Weather shocks provide an important exogenous supply-side shock to the economy. Given the sectoral structure of the economy, for some of the period the agricultural sector had a large exogenous impact on macro-economic fluctuations. The magnitude of this impact was highest in the pre-1890 period. As late as 1868 the domestic agricultural sector provided $80 \%$ of domestic food supply, employed $22 \%$ of the labour force and generated $17 \%$ of GDP. At the national level, given the relative decline of the sector over time, the effect of weather shocks on the macro-economy diminished over time.

The evidence considered suggests that there does not exist a simple coupling of weather cycles and economic cycles, as envisaged in the Jevons' sunspot theory of trade cycles. However, weather has a significant effect across a number of important sectors. Moreover, given the specific historical period significant macroeconomic effects are generated.

Appendix 1. Data sources

\begin{abstract}
Agricultural sector
British agricultural production data are from Lewis (1978, p. 260-263); the Lewis index is an annual extension of O'jala's (1952) index, which is given only for specific benchmark years. Labour input is expressed in man-years. An annual time-series is derived for the agricultural working population by assuming that the ratio of the agricultural labour force to the total working population changed on a linear path over the benchmark cen-
\end{abstract}

sus years. Adjusting the agricultural working population for the unemployment rate using Feinstein (1972) provides an estimate of the agricultural labour input series. Figures for capital stock are from Feinstein \& Pollard (1988).

Annual average temperature data are from Parker et al. (1992), which cover central England. Annual total rainfall data were reported by Wigley et al. (1984), which relate to Britain. 
Appendix 1 (continued)

\section{Construction sector}

The construction sector's output and input data for the pre1913 period are only available at the annual frequency. The construction output series used in the estimations for this paper is Feinstein's revisions to Lewis (1978). Up to now the figures used by researchers are those based on the work of Lewis (1978, Table A1). However, it is clear that Lewis used a number of arbitrary assumptions in generating time-series data for construction output. For example, in the case of estimating commercial property built in any year, Lewis simply imposes the cycle of marriages on the data. Such data generation assumptions are not testable (and unlikely to hold), limiting the usefulness of the data. In revising the new building series Feinstein has avoided the use of such a priori assumptions. Given the absence of historical data on repairs, this series has to be constructed by assumption. The focus of this paper is to explain the variation in new building construction, because we do not have any genuine data on repairs for this period.

Labour input is expressed in man years, based on census information (Lewis 1978, p. 265); an annual series is derived by assuming that the ratio of construction labour force to the total working population changed on a linear path over the benchmark census years. The figures are adjusted to allow for the level of unemployment as reported in Feinstein (1972, T123-4) to give the labour input series.

The weather data relate to daily central England temperatures (Parker et al. 1992) and monthly central England rainfall (Wigley et al. 1984). From these observations we are able to derive a number of weather measures at the seasonal and annual frequencies. The data also allow us to construct series for frost days (Watkins 1991). Although we experimented with models that used high-frequency weather data to explain annual economic data, the best fitting models were those that related annual economic data to annual weather data. We also found frost days to be statistically insignificant. Hence, the models reported in this paper use annual rainfall and temperature weather data.

\section{Coal sector}

Domestic coal consumption is calculated from Mitchell (1992, Tables D2 \& D11) as total coal output minus coal exports. The industrial production index is from Mitchell (1992, Table D1). Real wages are calculated as average money earnings (Feinstein 1990) deflated by the cost of living index (Feinstein 1991, Table 6.4). The price index used is the fuel and light cost component of Feinstein's cost of living index (1991, Table 6.4, p.170-171)
Acknowledgements. The Leverhulme Trust and the ESRC supported the research for this paper. We would like to thank Charles Feinstein for allowing us to use his new construction sector output series. The article has benefited from comments from Andrew Harvey and 3 anonymous referees.

\section{LITERATURE CITED}

Chambers RG (1988) Applied production analysis. A dual approach. Cambridge University Press, Cambridge

Davies M (1960) Grid system operation and the weather. Weather 15:18-24

Dryar HA (1949) Load dispatching and philadelphia weather. Bull Am Meteorol Soc 30:159-167

Elkhafif MAT (1996) An iterative approach for weather-correcting energy consumption data. Energy Econ 18: 221-230

Engle RF, Granger CW, Rice J, Weiss A (1986) Semiparametric estimates of the relation between weather and electricity sales. J Am Stat Assoc 81:310-320

Feinstein $\mathrm{CH}$ (1972) National income, expenditure and output of the UK, 1856-1965. Cambridge University Press, Cambridge

Feinstein CH (1990) New estimates of average earnings in the United Kingdom 1880-1913. Econ Hist Rev XLIII(4): 595-632

Feinstein CH (1991) A new look at the cost of living 1870-1914. In: Foreman-Peck J (ed) New perspectives on the late Victorian economy. Cambridge University Press, Cambridge

Feinstein CH, Pollard S (1988) Studies in capital formation in the United Kingdom 1750-1920. Oxford University Press, Oxford

Feinstein CH, Matthews RCO, Odling-Smee J (1982) The timing of the climacteric and its sectoral incidence in the UK
1873-1913. In: Kindleberger, Di Tella C (eds) Economics in the long view: essays in honour of W.W. Rostow, Vol 3. Macmillan, London

Harris DW (1964) The relationship between relative humidity, temperature and demand for electric power at peak periods. NZ Electr J 37(7):169

Hsiao C, Mountain DC, Chan MWL, Tsui KY (1989) Modelling Ontario regional electricity system demand using a mixed fixed and random coefficients approach. Reg Sci Urban Econ 19:565-587

Jevons WS (1884) Investigations in currency and finance. Macmillan, London

Jones EL (1964) Seasons and prices. George Allen and Unwin, London

Khatri, YJ, Solomou SN (1995) The impact of weather on UK agricultural production, 1953-1990. DAE Working Paper 9532, Cambridge University

Khatri, YJ, Solomou SN, Wu W (1998) The impact of weather on UK agricultural production, 1867-1913. Res Econ Hist 18:83-102

Lamb HH (1982): Climate, history and the modern world. London

Lewis WA (1978) Growth and fluctuations 1870-1913. George Allen and Unwin, London

Maunder WJ (1986) The uncertainty business: risks and opportunities in weather and climate. Methuen, London

Mitchell BR (1992) International historical statistics: European 1750-1988, 3rd edn. Macmillan, London

Nye RH (1965) The value of services provided by the Bureau of Meteorology in planning within the State Electricity commission of Victoria, what is weather worth? Bureau of Meteorology, Melbourne, p 87-91

O'jala EM (1952) Agriculture and economic progress. Oxford University Press, London

Oury B (1959) Allowing for weather in crop production model 
building. J Farm Econ 41:70-76

Parker DE, Legg TP, Folland CK (1992) A new daily Central England Temperature Series, 1772-1991. Int J Climatol 12:317-342

Parry ML (1981) Climatic change, agriculture and settlement. Dawson, Folkestone

Perry PJ (1973) British agriculture 1875-1914. Methuen \& Co, London

Prior MJ (1989) Weather interference with construction operations: Met Office Climatological Services. In: Harrison SJ, Smith K (eds) Weather sensitivity and services in Scotland. Scottish Academic Press, Edinburgh

Rodda JC, Downing RA, Law FM (1976) Systematic hydrology. Butterworths, London

Russo JA Jr (1966) The impact of weather on the construction industry of the United States. Bull Am Meteorol Soc 47: 967-972

Solomou SN (1987) Phases of economic growth, 1850-1973: Kondratieff waves and Kuznets swings. Cambridge University Press, Cambridge

Solomou SN, Weale MR (1993) Balanced estimates of national accounts when measurement errors are autocorrelated: The UK 1920-38. J R Stat Soc Ser A 156(Part 1):89-105

Editorial responsibility: Michael Hulme, Norwich, United Kingdom
Solomou S, Wu W (1997) The impact of weather on construction sector output variations, 1955-1989. DAE Working Paper 9722, Cambridge University

Sowell F (1992) Maximum likelihood estimation of stationary univariate fractionally integrated time series methods. Econometrica 59:165-188

Stephens FB (1951) A method of analysing weather effects on electrical power consumption. Bull Am Meteorol Soc 32: $16-20$

Thomas B (1973): Migration and economic growth. Cambridge University Press, Cambridge

Thornthwaite CW (1948) An approach toward a rational classification of climate. Geogr Rev 38(1):78-92

Watkins C (1991) The annual period of freezing temperatures in Central England: 1850-1989. Int J Climatol 2:889-896

Wigley TML, Atkinson TC (1977) Dry years in South-East England since 1698. Nature 265:431-434

Wigley TML, Lough JM, Jones PD (1984) Spatial patterns of precipitation in England and Wales and a revised, homogeneous England and Wales precipitation series. J Climatol 4:1-25

Zahorchak M (1983) Climate: the key to understanding business cycles. Tide Press, Linden, NJ

Submitted: March 23, 2001; Accepted: August 29, 2001

Proofs received from author(s): February 4, 2002 